\title{
Follow-up of participants in the Canadian Association of Gastroenterology Scholars' Program, 2006 to 2012
}

\author{
Mindy CW Lam MD FRCPC 1 , Michael SL Sey MD FRCPC ${ }^{2}$, Jamie Gregor MD FRCPC ${ }^{2,3}$, Clarence Wong MD FRCPC 1,3
}

\begin{abstract}
MCW Lam, MSL Sey, J Gregor, C Wong. Follow-up of participants in the Canadian Association of Gastroenterology Scholars' Program, 2006 to 2012. Can J Gastroenterol Hepatol 2014;28(2):94-96.
\end{abstract}

The Canadian Association of Gastroenterology (CAG) Scholars' Program (previously known as the Bright Lights Course) is designed to encourage trainees to consider a subspecialty career in gastroenterology. A formal analysis of the Scholars' Program performed in 2007 revealed that $82 \%$ of participants invited to the program pursued or were planning to pursue a career in gastroenterology. The positive results are consistent with the CAG's strategic plan of developing "the next generation of gastroenterology clinical practitioners, researchers, educators, and leaders" and to "attract, train, and retain the best and the brightest to gastroenterology". The present study was a follow-up analysis of participants in the Scholars' Program between 2006 and 2012. Although $93.1 \%$ of participants had an interest in gastroenterology before attending the Scholars' Program, the majority $(68.7 \%$ ) reported a greater interest in gastroenterology after the program. Similar to the study from 2007, the present study again illustrates the importance and success of the Scholars' Program in generating interest and retaining candidates in gastroenterology.

\author{
Le suivi des participants au programme de boursiers \\ de l'Association canadienne de gastroentérologie, de \\ 2006 à 2012
}

Le programme de boursiers (autrefois le Bright Lights Course) de l'Association canadienne de gastroentérologie (ACG) est conçu pour inciter les stagiaires à envisager une carrière de surspécialité en gastroentérologie. Une analyse officielle du programme de boursiers effectuée en 2007 a révélé que $82 \%$ des participants qui y étaient invités menaient ou prévoyaient mener une carrière en gastroentérologie. Les résultats positifs concordent avec le plan stratégique de l'ACG qui vise à former " la prochaine génération de praticiens cliniques, de chercheurs, d'enseignants et de chefs de file en gastroentérologie » et à « attirer, former et retenir en gastroentérologie les meilleurs et les plus intelligents ». La présente étude était une analyse de suivi des participants au programme entre 2006 et 2012. Même si 93,1 \% des participants s'intéressaient à la gastroentérologie avant d'assister au programme de boursiers, la majorité $(68,7 \%)$ déclaraient s'y intéresser davantage après le programme. À l'instar de l'étude de 2007, la présente étude démontre de nouveau l'importance et le succès du programme de boursiers à susciter de l'intérêt et à retenir des candidats en gastroentérologie.

Key Words: Bright Lights Course; Canadian Digestive Diseases Week; Scholars' Program

$\mathrm{T}$ he Canadian Association of Gastroenterology (CAG) Scholars' Program was founded in 2001, when it was previously known as the Bright Lights Course. The purpose of the program is to encourage trainees to consider a subspecialty career in gastroenterology. Its target audience includes senior medical students, and first- and second-year internal medicine and pediatric residents. Candidates are nominated by medical schools across Canada and, typically, one to three candidates from each school are selected to participate.

This two-day program is held annually in conjunction with the Canadian Digestive Diseases Week conference. Participants are given an opportunity to interact with world leaders in academic and clinical gastroenterology. The program addresses recent research advances, medical education, career development and ethics challenges. The curriculum is interactive in nature. This is achieved through small group activities, presentations as well as hands-on learning with Fibroscan (Echosens, France) and endoscopy simulators.

Gastroenterology manpower is a concern in Canada. A recent analysis revealed that while the United States has, on average, 3.9 gastroenterologists per 100,000 population, Canada has only 1.83 per 100,000. A comparison of five countries (United States, France, Australia, Canada and United Kingdom) showed that Canada had the fourth-lowest ratio of gastroenterologists per population (1).

A formal analysis of the Scholars' Program was performed in 2007 (2). The results revealed that $82 \%$ of participants invited to the program pursued or were planning to pursue a career in gastroenterology. Of the candidates who were undecided on a subspecialty before the program,
39\% pursued gastroenterology after the Scholars' Program. Thus, the program appeared to support the CAG strategic plan of attracting the best and brightest to gastroenterology (3).

The present study was a follow-up analysis of the Scholars' Program between 2006 and 2012.

\section{METHODS}

A survey consisting of questions specifically addressing participants' interest in gastroenterology before and after the Scholars' Program and current career status was distributed through an Internet-based survey (Survey Monkey [4]). The survey was scored on a five-point Likert scale $(1=$ strongly disagree; 2 = disagree; $3=$ neutral; 4 = agree; and 5 = strongly agree); a score of 4 or 5 was considered to be a positive response. All participants in the course between 2006 and 2012, inclusive, were sent an electronic survey by e-mail. Participants were given two months to complete the survey with a reminder at one month and six weeks. Because of suboptimal response (response rate of $46.6 \%$ ), the survey was redistributed eight months later to nonresponders only. Participants were given one month to complete the survey with a reminder at two weeks and three weeks. Results were analyzed using a spreadsheet program (Excel, Microsoft Corporation, USA).

\section{RESULTS}

Of 221 Scholars' Program participants, 131 responded to the survey, yielding a response rate of $59.3 \%$. The average age of surveyed participants was 31.4 years and $52.9 \%$ were male $(\mathrm{P}=0.6)$ (Table 1$)$. The

\footnotetext{
${ }^{1}$ Deparment of Medicine (Gastroenterology), University of Alberta, Edmonton, Alberta; ${ }^{2}$ Department of Medicine (Gastroenterology), University of Western Ontario, London Health Sciences Centre, London, Ontario; ${ }^{3} \mathrm{Co}-$ Chairs, CAG Scholars' Program

Correspondence: Dr Clarence Wong, Division of Gastroenterology, Royal Alexandra Hospital, 10240 Kingsway Avenue Northwest, \#218 Comm Services

Centre, Edmonton, Alberta T5H 3V9. Telephone 780-735-6838, fax 780-735-6792,e-mail ckw3@ualberta.ca
}

Received for publication October 2, 2013. Accepted October 6, 2013 
TABLE 1

\section{Demographics}

\begin{tabular}{lc}
\hline Characteristics $(\mathbf{n}=103)$ & $\mathbf{n}(\%)$ \\
\hline Sex & $70(53.4)$ \\
Male & $61(46.6)$ \\
Female & $31.4 \pm 3.9$ \\
Age, years, mean \pm SD & \\
Current status & $68(51.9)$ \\
Gastroenterology & $26(19.8)$ \\
$\quad$ Gastroenterologist & $42(32.1)$ \\
$\quad$ Gastroenterology fellow & $33(25.2)$ \\
\hline
\end{tabular}

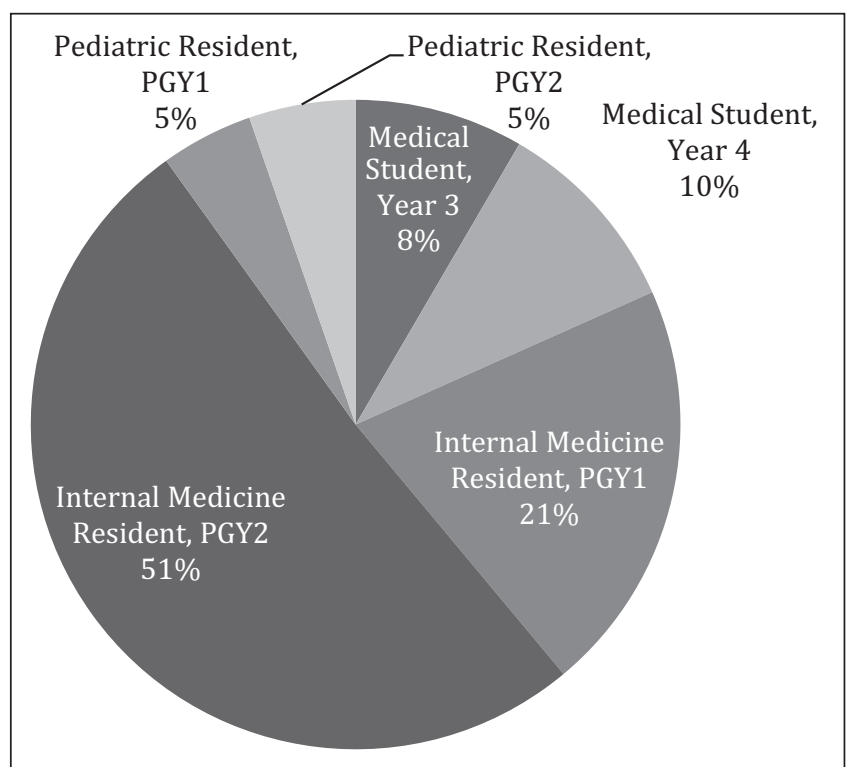

Figure 1) Level of training at the time of the Scholars' Program. PGY Postgraduate year

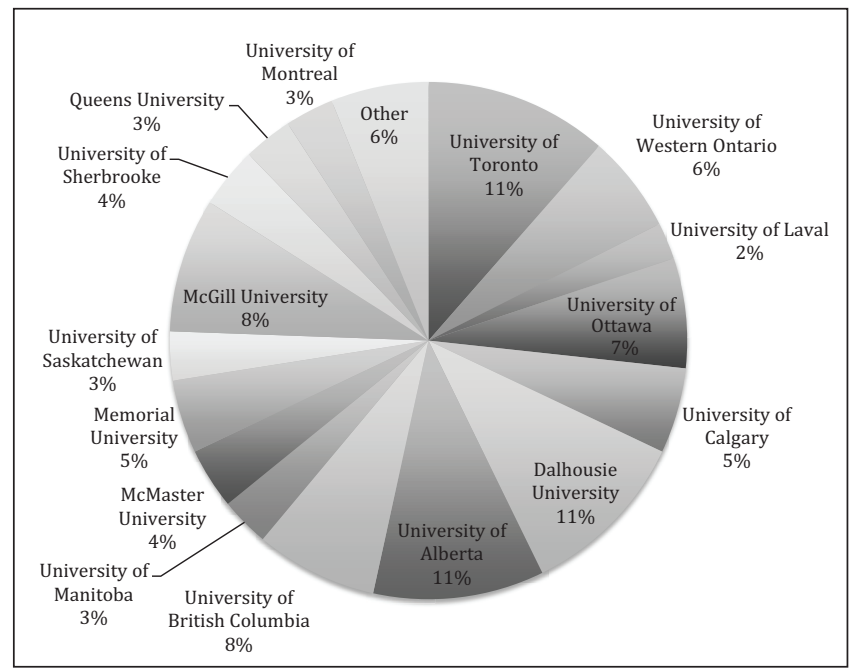

Figure 2) Distribution of participants according to the medical school granting the medical degree

survey participants were evenly distributed among each of the program years from 2006 to $2012(\mathrm{P}=0.3)$. Most were postgraduate year 2 internal medicine residents at the time of program participation $(51.1 \%)$ (Figure 1). The majority of participants were from the University of Alberta (Edmonton, Alberta), University of Toronto (Toronto, Ontario) and Dalhousie University (Halifax, Nova Scotia) (Figure 2).

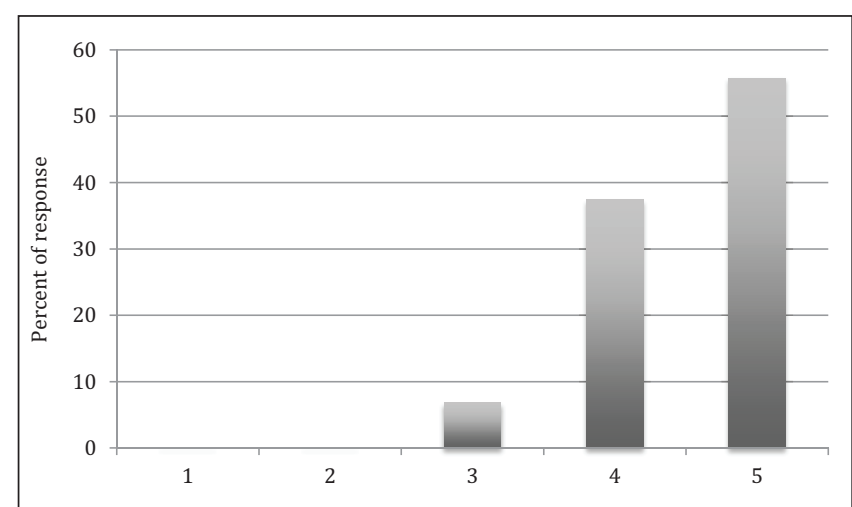

Figure 3) Per cent of response to 'I had an interest in gastroenterology before the Scholars' Program' ( 1 = strongly disagree; 5 = strongly agree)

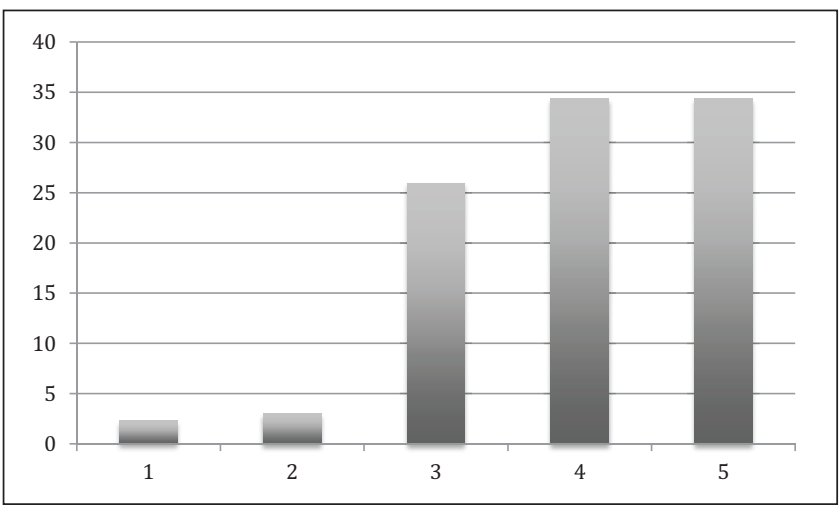

Figure 4) Per cent of response to "I had more interest in gastroenterology after the Scholars' Program" (1 = strongly disagree; 5 = strongly agree)

Before the Scholar's Program, $93.1 \%$ of participants had an interest in gastroenterology (Figure 3). On completion of the program, $68.7 \%$ of participants had a greater interest in gastroenterology (Figure 4); 65.6\% participants found the program important to their decision-making process for a subspecialty career. More than one-half (53.4\%) of respondents found that the program was valuable for their curriculum vitae and their success with the Canadian Resident Matching Service, and $87.0 \%$ of participants would recommend the Scholars' Program to their junior colleagues.

Currently, $51.9 \%$ of the program participants are practising gastroenterology or are in a gastroenterology fellowship program.

\section{DISCUSSION}

The Scholars' Program has been providing quality education for students and residents interested in gastroenterology for $>10$ years. The present report is an updated review of the program over a six-year period (2006 to 2012).

There was a fair response rate $(59.3 \%)$ to the survey. The survey was distributed twice because the initial response rate was low. The reason for this low response rate may be due to the busy schedules of students, residents and physicians, and the frequent need to relocate during medical training. Similar to the 2007 study, most participants were residents, with equal distribution between males and females. A trend toward more graduates of the Scholar's Program intent on pursuing a career in gastroenterology compared with our previous study was observed, although differences in methodology precludes direct comparison between the two studies (2).

It is interesting that most participants completed their undergraduate medical degree from the University of Alberta, University of Toronto and Dalhousie University. Although our data were not adjusted for medical school size, because this is a constantly changing variable, it is noteworthy that Dalhousie has one of the smallest 
programs in the country yet is one of the greatest contributor to the Scholars' Program. This may reflect career interest developed during the gastroenterology block in medical school training programs.

A limitation to the present survey-based study was recall bias; future directions would be a prospective study to survey the participants before and after the Scholars' Program.

Similar to our study from 2007, the present study again illustrates the importance and success of the Scholars' Program in generating interest and retaining candidates in gastroenterology.

\section{CONCLUSION}

The Scholars' Program is a valuable Canadian program that is ensuring the persistent growth in the next generation of gastroenterologists.

\section{REFERENCES}

1. Moayyedi P, Tepper J, Hilsden R, Rabeneck L. International comparisons of manpower in gastroenterology. Am J Gastroenterol 2007;102:478-81.

2. Nazareno J, Wong C, Gregor J. Follow-up of past participants of the Canadian Association of Gastroenterology Scholars' Program (2001 to 2005) - where are they now? Can J Gastroenterol 2007;21:397-8.

3. Sherman PM, Fedorak RN, Leddin D, Wallace JL. Canadian Association of Gastroenterology 2004 strategic plan. Can J Gastroenterol 2004;18:125-6.

4. Survey Monkey. www.surveymonkey.com. 


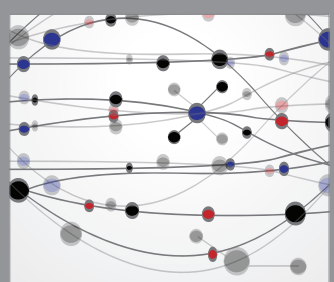

The Scientific World Journal
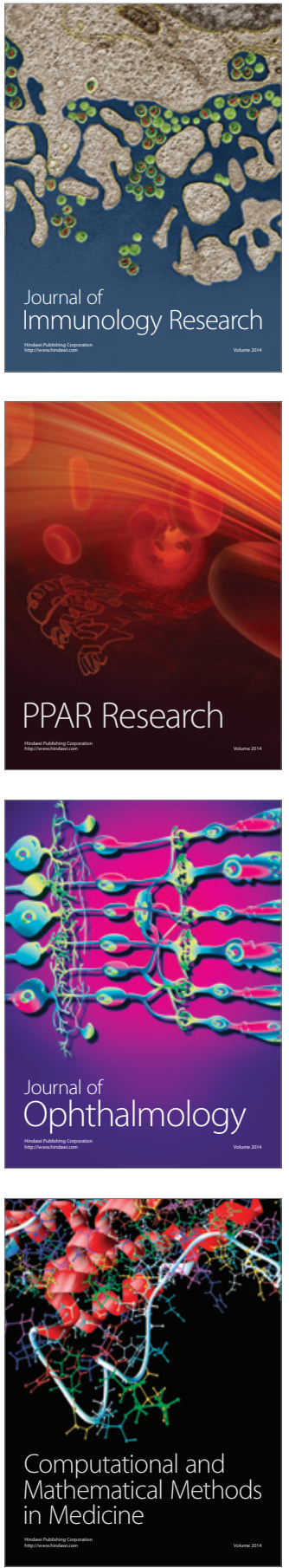

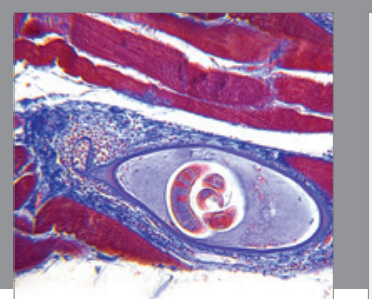

Gastroenterology Research and Practice

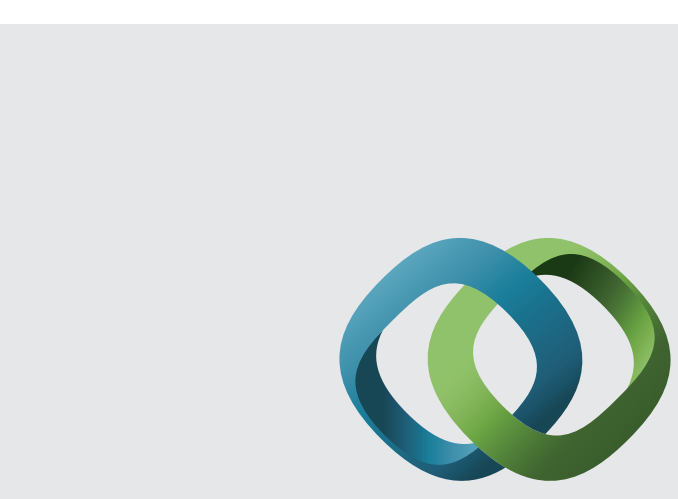

\section{Hindawi}

Submit your manuscripts at

http://www.hindawi.com
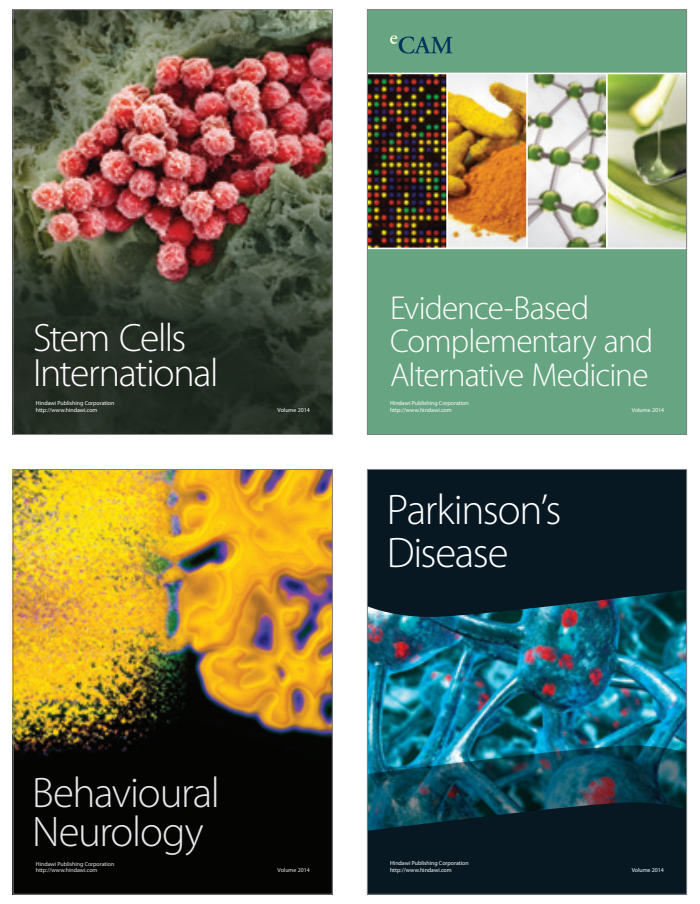
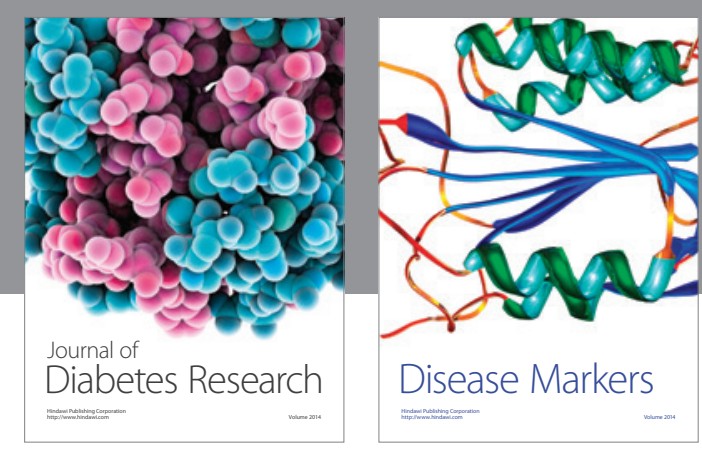

Disease Markers
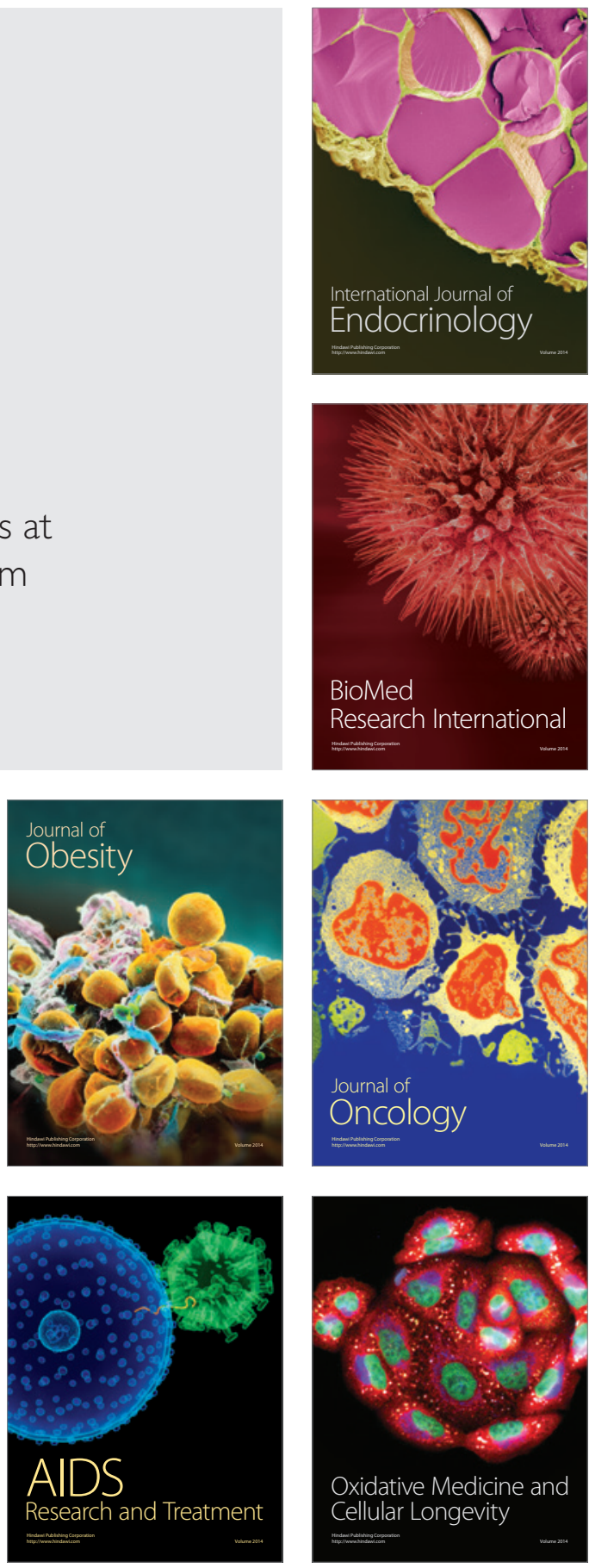